\title{
Replacement of Lead stabilizer in electroless Nickel-Boron baths: Synthesis and characterization of coatings from bismuth stabilized bath
}

\author{
L. Bonin *, V. Vitry, F. Delaunois \\ Metallurgy Lab, UMONS, 20 place du Parc, 7000 Mons, Belgium
}

\section{A R T I C L E I N F O}

\section{Article history:}

Received 26 July 2018

Received in revised form 20 September 2019

Accepted 3 October 2019

\section{Keywords:}

Electroless

Nickel-boron

Stabilizer

Bismuth

\begin{abstract}
A B S T R A C T
Only a few compounds have been completely characterized as stabilizers in alkaline electroless nickel-boron plating and most of them have serious impact on health or the environment. In this paper, the effects of bismuth salts on the bath stability and characteristics of electroless NiB deposits obtained from an alkaline electroless nickel bath reduced by borohydride are presented. The objective of this paper is to propose a healthy and environmental friendly electroless NiB coating. The process of production was maintained the same as traditional NiB to facilitate the industrial adaptation. Bismuth accelerates the rate of deposition up to $10^{-5} \mathrm{~mol} / \mathrm{L}$ and inhibits plating from a concentration of $0.01 \mathrm{~mol} / \mathrm{L}$. The bismuth ions in the NiB bath act as stabilizer but some bismuth also co-deposits with the nickel-boron coating, leading to a coating with $3 \mathrm{wt} \%$ bismuth. The coating presents a homogeneous surface morphology with a $15.11 \mu \mathrm{m} / \mathrm{h}$ plating rate in agitated and non-replenished bath. The X-ray diffraction patterns of electroless $\mathrm{NiB}$ coatings stabilized by $\mathrm{Bi}^{3+}$ exhibit a single broad peak, indicating a strong tendency to form amorphous structure. The coatings present the typical high hardness of NiB coatings $\left(830 \mathrm{hv}_{50}\right)$, with a relatively smooth surface. The wear behavior was characterized by ball-on-disc tests and a friction coefficient of 0.45 is obtained after $100 \mathrm{~m}$ of test with $5 \mathrm{~N}$ charge and an alumina ball. Scratch test results show the first damage after $16 \mathrm{~N}$. NiB-Bi coatings have impressive properties and can replace lead stabilized electroless NiB in different fields.
\end{abstract}

(c) 2019 Elsevier B.V. All rights reserved.

\section{Introduction}

Deposition of metals and alloys without an external current (electroless plating) allow plating on parts of very complex shapes, metallization of non-conductive surfaces (glass, ceramics, polymers, etc.) and selective deposition, allowing to plate only catalyzed areas of the substrate [1]. Nickel is the metal with the largest field of applications in terms of electroless plating. Brenner and Riddel discovered the electroless plating process in 1946 [2]. Electroless nickel-boron (NiB) baths, that use borohydride as a reducing agent, were developed in 1955 [3].

During electroless plating metal ions are reduced to metallic form by chemical agents (reducing agent). The reaction is due to the fact that an activated substrate develops a potential when it is dipped in the electroless plating solution, then, both positive and negative ions are attracted towards the substrate surface and release their energy through charge transfer processes. The reaction is autocatalytic and can easily be unstable if not controlled. In consequence a stabilizer is necessary to prevent or delay the spontaneous decomposition of electroless nickel plating solutions and regulate plating speed. However, only a few compounds have been completely characterized as stabilizers in alkaline electroless

\footnotetext{
* Corresponding author.

E-mail address: luiza.bonin@umons.ac.be (L. Bonin).
}

nickel-boron plating and most of them have serious impact on health or the environment.

Electroless nickel-boron possesses high hardness, natural lubricating properties, and good wear, abrasion and corrosion resistance [4-8]. NiB coatings are widely used in aerospace, automotive and defense industries particularly due to their high hardness and wear resistance. Another potential application of $\mathrm{NiB}$ coatings is the substitution of noble metals in semiconductors and printed circuits boards. However, in order to enter new fields of application $\mathrm{NiB}$ coatings need to answer emerging environmental concerns.

The coming into force of ELV, RoHS and WEEE environmental directives has brought new challenges to electroless nickel formulators: at the moment, most electroless Nickel-boron baths contain $\mathrm{Pb}^{2+}$ ions as an effective catalytic poison (stabilizer) for electroless nickel deposition. Bielinski et al. [9] studied the influence of 60 inorganic compounds on the electroless reduction of nickel from solutions containing sodium borohydride. However, none of the eco-friendly elements tested presented stabilizer properties. Some work was carried out on lead-free electroless NiP coatings [10-13]. However lead-free electroless NiB coatings are still not already available. It is thus necessary to provide the industry with alternate stabilizer that can efficiently replace lead salts, without the environmental and health issues associated with this metal. 
The present work has as a principal objective to introduce an alternative to $\mathrm{Tl}$ and $\mathrm{Pb}$-based electroless nickel processes which is completely free of toxic heavy metal stabilizers. Additionally, this work has the aim to develop a new bath that can be used in the installations already present in the electroless plating industry. The process to develop the new plating bath with bismuth stabilizer will first be discussed. In a second section, the properties of the new NiB-Bi coating will be presented because the incorporation of a new stabilizer in a plating solution may affect the composition and properties of the produced deposit. Finally, the properties of NiB-Bi will be compared to the traditional Pb-stabilized electroless nickel-boron.

\section{Materials and methods}

The present paper is composed of four parts. First, the assessment of the stabilization properties of $\mathrm{Bi}$, second the composition optimization of the bismuth stabilized plating bath, then the characterization of $\mathrm{NiB}-\mathrm{Bi}$ coatings, and finally the comparison of the properties of $\mathrm{NiB}-\mathrm{Bi}$ with traditional $\mathrm{NiB}-\mathrm{Pb}$.

\subsection{Electroless NiB bath}

The EN plating solution used in this study is composed of sodium borohydride $\left(\mathrm{NaBH}_{4}-99.9 \%\right)$ as reducing agent, nickel chloride hexahydrate $\left(\mathrm{NiCl}_{2} \cdot 6 \mathrm{H}_{2} \mathrm{O}-99 \%\right)$ as nickel source, ethylenediamine $\left(\mathrm{NH}_{2}-\mathrm{CH}_{2}-\mathrm{CH}_{2}-\mathrm{NH}_{2}-99 \%\right)$ as complexing agent and sodium hydroxide $(\mathrm{NaOH})$ as $\mathrm{pH}$ regulator. The temperature $\left(95 \pm 1{ }^{\circ} \mathrm{C}\right)$ and agitation $(300 \mathrm{rpm})$ were regulated by a hot plate with magnetic stirring. Bismuth tungsten oxide $\left(\mathrm{Bi}_{2}\left(\mathrm{WO}_{4}\right)_{3}-99.9 \%\right)$ was used as stabilizer in different concentrations. When the temperature reached $95^{\circ} \mathrm{C}$, the pretreated mild steel substrate was immersed in the solution. The chemistry of the solution (except the stabilizer content) and the mild steel pretreatment were kept identical to the lead stabilized baths, based on the work of Delaunois et al. [14].

\subsection{Measurement of the deposition rate}

An amount of $1 \mathrm{~L}$ of the plating solution described above (with varying bismuth salts concentration) and mild steel specimens with a total surface area of $25 \mathrm{~cm}^{2}$ were used to determine the effect of stabilizer concentration on the deposition rate. The experiment was carried out at a temperature of $95^{\circ} \mathrm{C}$. Mild steel substrate was pretreated as described by Delaunois [17] and directly immersed in the solution. After $1 \mathrm{~h}$, the specimen was removed from the bath, rinsed with distilled water and naturally dried. It was then weighed on an analytical balance (precision of $0.1 \mathrm{mg})$. The deposition rate $\mathrm{R}(\mu \mathrm{m} / \mathrm{h})$ was calculated as follow

$R=\frac{W x 10^{4}}{A \rho t}$

where:

$\mathrm{W}=$ the weight of plating layer in grams $(\mathrm{g})$.

$\mathrm{A}=$ the plating area in square centimeters.

$\rho=8.3 \mathrm{~g} / \mathrm{cm}^{2}$ is taken as the density of $\mathrm{NiB}$ alloy

by assuming a B-content of approximately $6 \%$.

$t=$ time in hours.

\subsection{Bath stability test}

The effect of stabilizer concentration on bath stability was characterized using $250 \mathrm{ml}$ of the plating solution. The solution, complete with reducing agent was heated and maintained at the plating temperature without immersing any sample. Time was recorded from the moment the solution reached $95^{\circ} \mathrm{C}$ up to the moment when the solution started

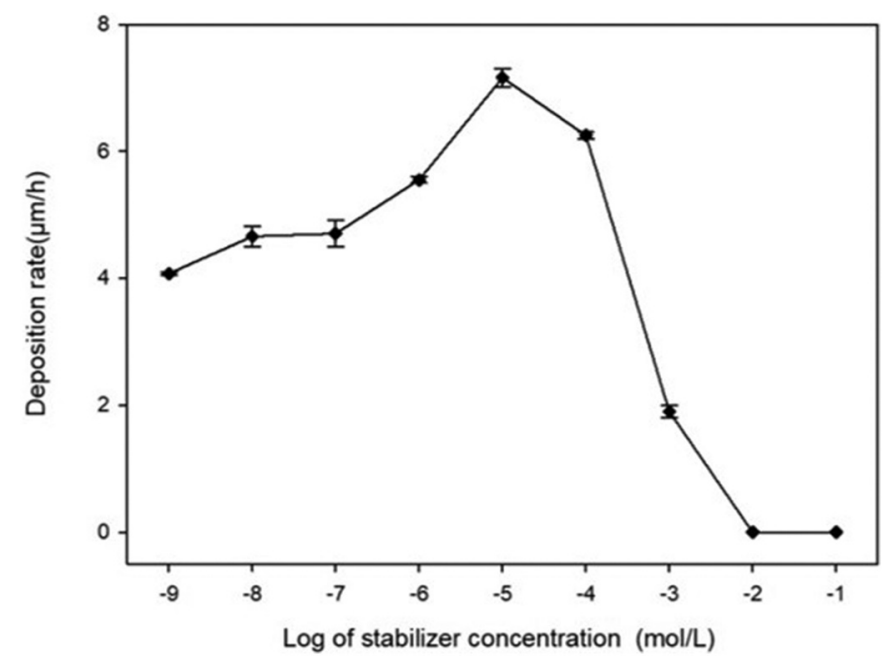

Fig. 1. Effect of Bismuth tungsten oxide concentration on deposition rate of electroless nickel.

decomposing. The end point, or the onset of bath decomposition, was defined as the time when dark precipitates appeared in the solution.

\subsection{Optimized electroless NiB-Bi bath}

The optimized bismuth-stabilized plating solution, determined from stabilization tests, from this paper, was used to produce NiB-Bi samples. The plating temperature was $95 \pm 1{ }^{\circ} \mathrm{C}$ and agitation at $300 \mathrm{rpm}$ was maintained during the $1 \mathrm{~h}$ plating process. Pretreated mild steel was used as the substrate. Two parameters are used to determine the optimized composition. The first one is the bath stability because a bath should be stable to run for long periods without plate-out. The second one was the plating rate: a higher plating rate signifies a shorter production time to generate the same thickness when compared to a lower plating rate. This optimized composition was obtained based on four tests presented in this work: the deposition rate and the bath stability for different stabilizer concentrations, the influence of $\mathrm{pH}$ on the plating rate and the plating rate and roughness variation for different concentrations of stabilizer and reducing agent.

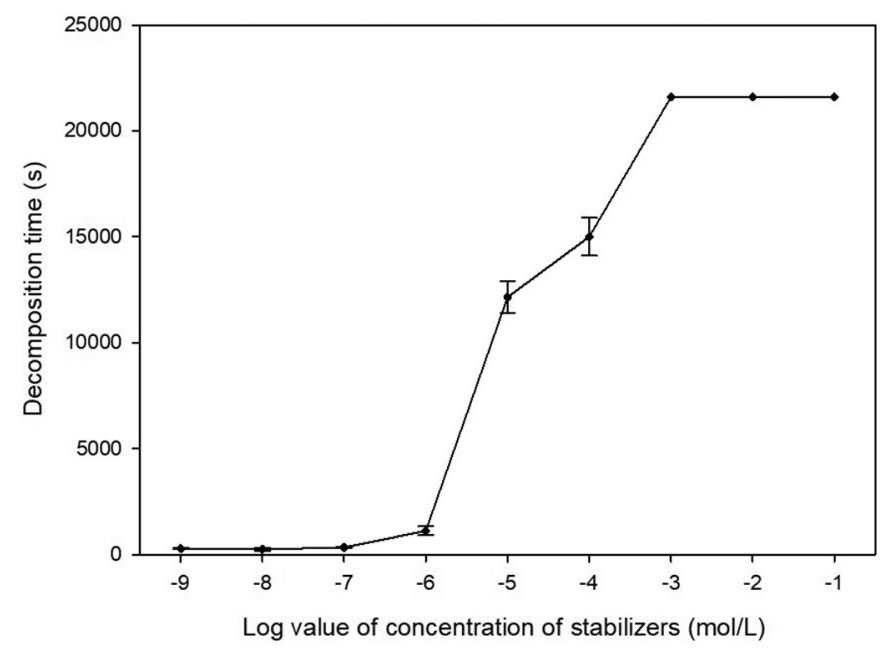

Fig. 2. Effect of Bismuth tungsten oxide concentration on bath life of electroless nickel. 
Table 1

Thickness of Nickel-boron deposits ( 1 h deposition) for different concentrations of bismuth tungsten oxide and sodium borohydride.

\begin{tabular}{|c|c|c|c|c|}
\hline \multirow[t]{2}{*}{ Borohydride g/L } & \multicolumn{4}{|l|}{$\mathrm{Bi}_{2}\left(\mathrm{WO}_{4}\right)_{3} \mathrm{~g} / \mathrm{L}$} \\
\hline & 0.018 & 0.022 & 0.026 & 0.030 \\
\hline 0.50 & $7.41 \pm 0.45 \mu \mathrm{m}$ & $8.75 \pm 0.37 \mu \mathrm{m}$ & $8.85 \pm 0.32 \mu \mathrm{m}$ & $8.47 \pm 0.49 \mu \mathrm{m}$ \\
\hline 0.60 & $10.31 \pm 0.31 \mu \mathrm{m}$ & $7.92 \pm 0.57 \mu \mathrm{m}$ & $9.01 \pm 0.29 \mu \mathrm{m}$ & $8.76 \pm 0.64 \mu \mathrm{m}$ \\
\hline 0.70 & $8.18 \pm 0.85 \mu \mathrm{m}$ & $6.96 \pm 0.39 \mu \mathrm{m}$ & $5.51 \pm 0.42 \mu \mathrm{m}$ & $4.31 \pm 0.25 \mu \mathrm{m}$ \\
\hline 0.80 & $5.85 \pm 0.54 \mu \mathrm{m}$ & $5.01 \pm 0.63 \mu \mathrm{m}$ & $3.87 \pm 0.89 \mu \mathrm{m}$ & $4.20 \pm 0.67 \mu \mathrm{m}$ \\
\hline
\end{tabular}

\subsection{Coatings characterization}

A digital optical microscope (Hirox KH-8700) was used for surface observations. A scanning electron microscope (SEM, Hitachi SU8020) was employed for the cross-section morphology analyses after mounting in resin, polishing with silicon carbide paper and diamond paste up to mirror finish, and etching with 4 vol\% Nital for $30 \mathrm{~s}$. X-ray diffraction was used to identify the structural state of the coatings. The apparatus used in this work was a Panalytical Empyrean 2 $2 \theta-\theta$ goniometer with $\mathrm{Cu}$ $\mathrm{K} \alpha(1.54$ Å) radiation. ICP-AES (Inductively Coupled Plasma - Atomic Emission Spectrometry was used for the measure of the boron and bismuth concentration. To obtain the global composition of the deposits, samples were dissolved in aqua regia. A Zeiss 119 SURFCOM 1400D3DF profilometer was used to measure the surface roughness with a cut-off length of $0.8 \mathrm{~mm}$ and Gaussian filter. A Mitutoyo HM-200 microhardness tester equipped with a Vickers and a Knoop indenter was used to measure cross-section hardness, with the following test parameters: load of $50 \mathrm{gf}$ applied for $20 \mathrm{~s}$. In views of estimating the adhesion of the deposits under external solicitations, scratch tests were carried out. A CSEM scratch tester machine with a diamond Rockwell stylus with a radius of $200 \mu \mathrm{m}$ was used to perform those tests. A linearly increasing load (from 0 to $150 \mathrm{~N}$ ) was employed in all cases, with a scratch velocity of $6.75 \mathrm{~mm} / \mathrm{min}$ and a scratch size of $10 \mathrm{~mm}$. Tribological behavior was investigated using ball-on-disc CSM microtribometer (without lubricants). The samples served as the disks and the counterparts were $6 \mathrm{~mm}$ diameter alumina balls (1400 $\mathrm{hv}_{50}$ ). The sliding speed, sliding distance, and normal load were respectively $10 \mathrm{~cm} / \mathrm{s}, 100 \mathrm{~m}$, and $5 \mathrm{~N}$. The specific wear rate (Ws) was calculated following the European standard EN 1017-13:2008, where Ws is the volume wear loss $\Delta \mathrm{V}$ divided by the applied load $\mathrm{F}_{\mathrm{N}}$ and the sliding distance $\mathrm{S}$.

Corrosion characterization was performed by Potentiodynamic polarization in $0.1 \mathrm{M} \mathrm{NaCl}$ solution with a Bio-logic SP-50 potentiostat.

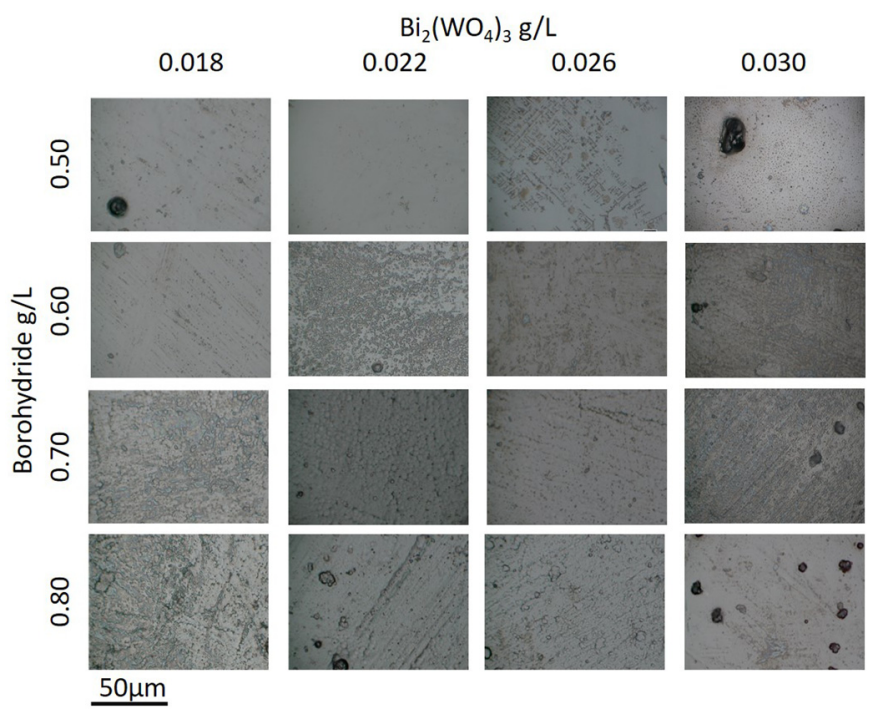

Fig. 3. Surface morphology of NiB-Bi coatings stabilized with different concentrations of bismuth tungsten oxide and sodium borohydride.
Before the polarization, the open circuit potential (OCP) was recorded for 20 min. Platinum plate and $\mathrm{Ag} / \mathrm{AgCl}$ ( $\mathrm{KCl}$ saturated) electrodes were used as counter and reference electrodes, respectively. A potential range of $\pm 0.25 \mathrm{~V} \mathrm{Vs} \mathrm{OCP,} \mathrm{at} 1 \mathrm{mV} / \mathrm{s}$ scan rate, was used. Salt spray tests were realized in a Q-FOG Cyclic corrosion tester, the samples were exposed to a $50 \mathrm{~g} / \mathrm{L} \pm 5 \mathrm{~g} / \mathrm{L} \mathrm{NaCl}$ solution. Salt spray tests were carried out according to ISO 9227 standard. Air pressure of the atomized saline solution was maintained in the range of 6-8 Bar. The tests were conducted for a variety of time periods ranging from $0.5 \mathrm{~h}$ to 10 days with intermediate periods of $1 \mathrm{~h}, 4 \mathrm{~h}, 8 \mathrm{~h}$ and 1, 2, 3, 4, 5, 7 days.

\section{Experimental results and discussion}

\subsection{Bath stability}

The stabilizing effect of Bi (III) was determined based on the correlation between the stabilizer concentration and the plating rate. In the case of elements with significant stabilization properties, the deposition should completely stop (plating rate equals to zero) for high stabilizer concentrations. On the other hand, elements that never stop the deposition are considered as not having any stabilizing properties [15].

Deposition rate versus concentration of bismuth oxide tungstate stabilizer is presented in Fig. 1. Bismuth oxide tungstate $\left(\mathrm{Bi}_{2}\left(\mathrm{WO}_{4}\right)_{3}\right)$ concentration in the solution varied in the range from $10^{-9}$ to $10^{-1} \mathrm{~mol} / \mathrm{L}$. The deposition rates were in the range of $0-7.16 \mu \mathrm{m} / \mathrm{h}$. The plating rate increases in the range from $10^{-9}$ to $10^{-5} \mathrm{~mol} / \mathrm{L}$, with the highest plating rate for a concentration of $10^{-5} \mathrm{~mol} / \mathrm{L}$. For concentrations of $\mathrm{Bi}_{2}\left(\mathrm{WO}_{4}\right)_{3}$ higher than $10^{-5} \mathrm{~mol} / \mathrm{L}$, the plating rate started to decrease. The complete inhibition of plating (plating rate of $0 \mu \mathrm{m} / \mathrm{h}$ ) is reached for concentrations superior to $10^{-2} \mathrm{~mol} / \mathrm{L}$. The results above show that $\mathrm{Bi}(\mathrm{III})$ has stabilizer properties for the present $\mathrm{NiB}$ electroless plating bath. A progressive increase in the rate of nickel deposition followed by a decrease is consistent with the results observed in the literature [16]. The enhancement of the nickel deposition at low stabilizer concentration is most probably linked to the decrease of the amount of nickel reduced spontaneously in the solution rather than on the substrate. The decrease

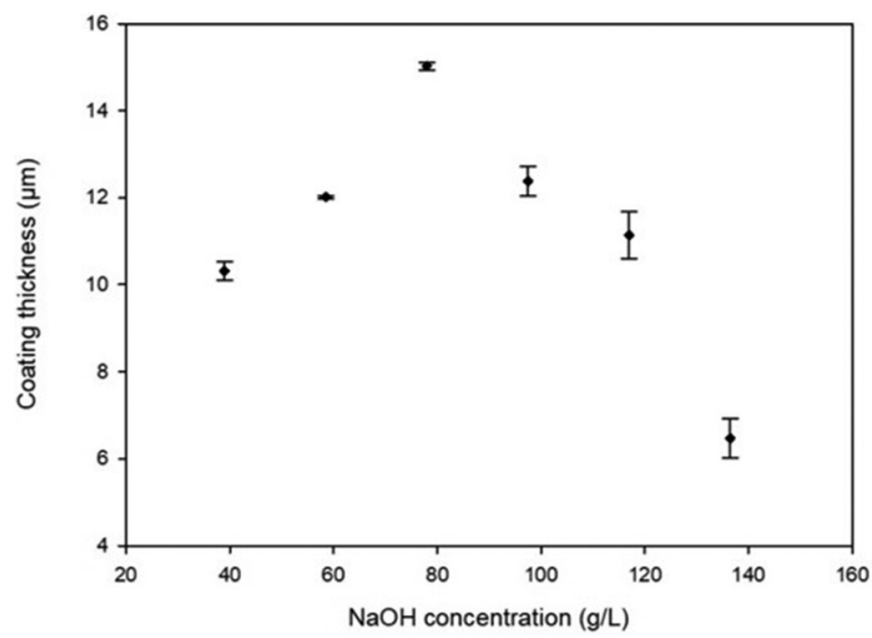

Fig. 4. Effect of $\mathrm{NaOH}$ concentration on the deposition rate of electroless nickel. 


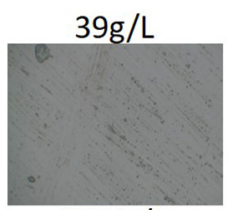

$97.5 \mathrm{~g} / \mathrm{L}$
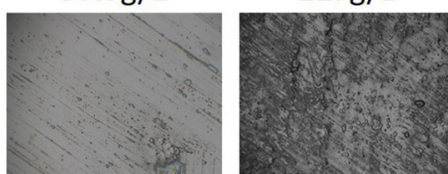

$58.5 \mathrm{~g} / \mathrm{L}$

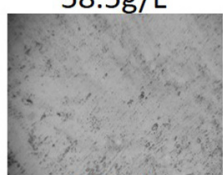

$117 \mathrm{~g} / \mathrm{L}$

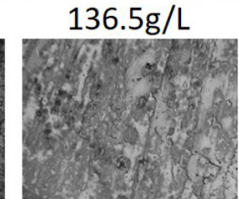

$50 \mu \mathrm{m}$

Fig. 5. Effect of NaOH concentration on the surface morphology of NiB-Bi coatings.

in the deposition rate at with high concentrations of $\mathrm{Bi}(\mathrm{III})$ is attributed to a reduction in the number of catalytic sites on the substrate surface due to adsorption of the bismuth atoms on top of the catalytic surface, limiting the catalytic reaction and consequently the deposition. (See Fig. 2)

The bath stability test shows a significant increase in bath stability with the addition of $\mathrm{Bi}(\mathrm{III})$. The bath life increased from $300 \mathrm{~s}$ to $15,000 \mathrm{~s}$ as the stabilizer concentration was increased from $10^{-9} \mathrm{~mol} / \mathrm{L}$ to $10^{-4} \mathrm{~mol} / \mathrm{L}$. For stabilizer concentrations equal or superior to $10^{-3} \mathrm{~mol} / \mathrm{L}$, bath decomposition was not observed after $21,600 \mathrm{~s}$ and the test was stopped after that time because baths with such high concentrations in bismuth ions do not present significant deposition in the plating rate test. The bath stability test results show that $\mathrm{Bi}(\mathrm{III})$ has stabilizer properties for the NiB electroless bath. A progressive increase in the time until decomposition was expected as the increase in the $\mathrm{Bi}(\mathrm{III})$ species decreases the catalytic activity. When compared with other green stabilizers used in electroless nickel deposition, the time before decomposition for a bath stabilized by Bi(III) is impressive: previous works showed $185 \mathrm{~s}$ until the decomposition for a $\mathrm{NiP}$ bath with benzotriazole and 12,000 s until the decomposition for a NiP bath with organic heterocycles containing sulfur [17].

\subsection{Composition optimization}

Taking the tests above as a guide, bismuth tungsten oxide has proven to have interesting stabilizer properties. However, even if the bath with $10^{-5} \mathrm{~mol} / \mathrm{L}$ of bismuth tungsten oxide presents positive results for the bath stability, some characteristics might be improved with composition modifications. To improve the plating rate and surface finishing, three different parameters are optimized. The first one is the concentration of $\mathrm{Bi}(\mathrm{III})$ : the stabilizer concentration is quite critical to its stabilization effect, excess quantities completely stop the plating and low concentrations are responsible for bath decomposition [1]. The second is the reducing agent concentration: Gorbunova et al. [10] proved that the amount of sodium borohydride also influences the bath stabilization and plating rate of electroless NiB bath. The third parameter is the $\mathrm{pH}$ : Lin et al. [18] showed that, as the $\mathrm{pH}$ increases, the plating rate also increases in an electroless nickel plating bath.

Coatings morphology and plating rate were selected as the main parameters to reach one optimized composition for NiB-Bi baths.

To optimize bath composition, four concentrations of bismuth tungsten oxide $(0.018 \mathrm{~g} / \mathrm{L} ; 0.022 \mathrm{~g} / \mathrm{L} ; 0.026 \mathrm{~g} / \mathrm{L}$ and $0.030 \mathrm{~g} / \mathrm{L})$ and five concentrations of sodium borohydride $(0.40 \mathrm{~g} / \mathrm{L}, 0.50 \mathrm{~g} / \mathrm{L}, 0.60 \mathrm{~g} / \mathrm{L}, 0.70 \mathrm{~g} / \mathrm{L}$ and $0.80 \mathrm{~g} / \mathrm{L}$ ) were tested. The plating rate in $\mu \mathrm{m} / \mathrm{h}$ for each case is presented in Table 1 . The characterization (plating rate) of samples plated with different concentrations of Bismuth tungsten oxide and sodium borohydride, shows that the samples obtained with $0.018 \mathrm{~g} / \mathrm{L}$ of bismuth tungsten oxide and $0.6 \mathrm{~g} / \mathrm{L}$ of sodium borohydride are the best candidates for an optimized composition: those samples reached the highest thickness $(10.31 \mu \mathrm{m}$ in $1 \mathrm{~h})$.

Fig. 3 shows the surface morphology of these samples after $1 \mathrm{~h}$ of deposition. The substrates coated with $0.018 \mathrm{~g} / \mathrm{l}$ of bismuth tungsten oxide presented the best results among the different formulations. Through the use of 3D optical microscopy, it is possible to observe a smooth surface, without any precipitates on it. The thickness of these coating is also in the acceptable range for an electroless process, except with $0.80 \mathrm{~g} / \mathrm{l}$ of sodium borohydride.

The substrates coated with $0.022 \mathrm{~g} / \mathrm{l}$ of bismuth tungsten oxide present a good surface morphology. When combined with $0.70 \mathrm{~g} / \mathrm{l}$ of sodium borohydride, a typical cauliflower structure is even obtained. However, the coatings obtained with this bismuth tungsten oxide were never thick enough, whatever the sodium borohydride concentrations tested.

The substrates coated with $0.026 \mathrm{~g} / \mathrm{l}$ of bismuth tungsten oxide present an adequate surface morphology, but with particles attached. By employing $0.50 \mathrm{~g} / \mathrm{l}$ and $0.60 \mathrm{~g} / \mathrm{l}$ of sodium borohydride, the deposition thickness was in the reasonable range, while in the case of $0.70 \mathrm{~g} / \mathrm{l}$ and $0.80 \mathrm{~g} / \mathrm{l}$, the resultant thickness was below expectations.

Finally, the substrates coated with $0.030 \mathrm{~g} / \mathrm{l}$ of bismuth tungsten oxide presented an irregular, non uniform, morphology due to the presence of attached nickel particles on the surface. In addition, their achieved thickness is relatively low.

The parameters that provided the best results $(0.018 \mathrm{~g} / \mathrm{L}$ of bismuth tungsten oxide and $0.6 \mathrm{~g} / \mathrm{L}$ of sodium borohydride) were then used for the $\mathrm{pH}$ optimization test. 6 different concentrations of $\mathrm{NaOH}$, all equal or higher than the initial concentration, to increase the plating $\mathrm{pH}$, were tested: $39 \mathrm{~g} / \mathrm{L}, 58.5 \mathrm{~g} / \mathrm{L}, 78 \mathrm{~g} / \mathrm{L}, 97.5 \mathrm{~g} / \mathrm{L}, 117 \mathrm{~g} / \mathrm{L}$, and $136.5 \mathrm{~g} / \mathrm{L}$.

Evolution of plating rate with $\mathrm{NaOH}$ concentration is presented in Fig. 4. The highest plating rate was obtained for the bath with $78 \mathrm{~g} / \mathrm{L}$ of sodium hydroxide. The plating rate increases from $10.31 \mu \mathrm{m} / \mathrm{h}$ to $15.02 \mu \mathrm{m} / \mathrm{h}$ with the increase of $\mathrm{NaOH}$ between 39 and $78 \mathrm{~g} / \mathrm{L}$. For $\mathrm{NaOH}$ concentrations higher than $78 \mathrm{~g} / \mathrm{L}$, nickel hydroxide is formed in the bottom of the beaker and the plating rate starts to decreases.

The coatings surface morphology images are presented in Fig. 5 . The six surface morphologies can be divided into two different groups. An excellent surface finishing is presented for the samples with sodium hydroxide equal or smaller than $78 \mathrm{~g} / \mathrm{L}$. The sample with the highest
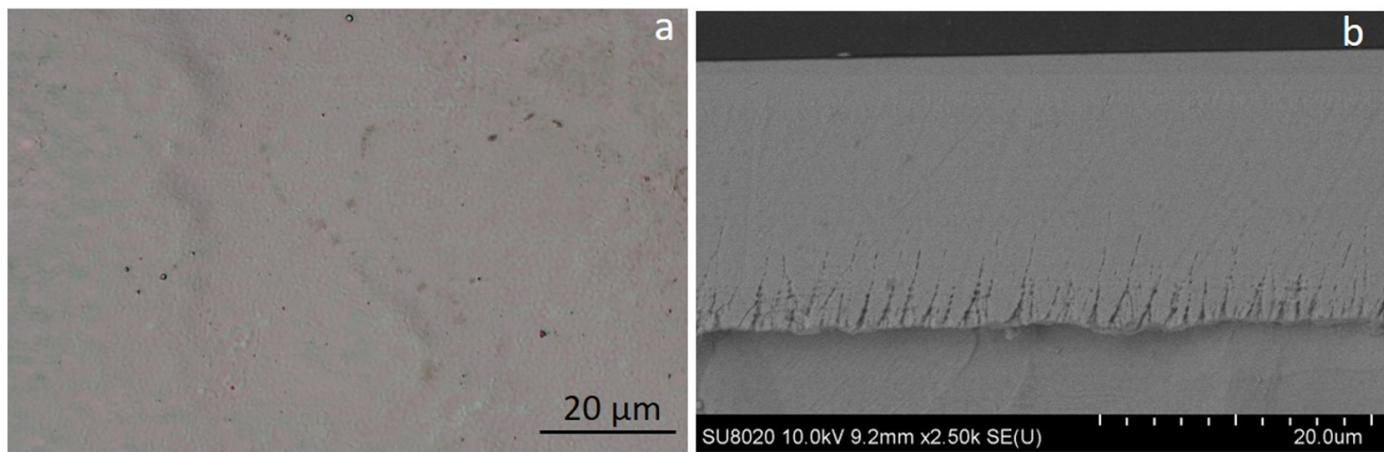

Fig. 6. Morphology of NiB-Bi samples, (a) surface morphology of the coated samples (b) SEM cross-section morphology. 
Table 2

Composition of electroless nickel boron stabilized by bismuth coatings.

\begin{tabular}{llll}
\hline Element & $\mathrm{Ni}$ & $\mathrm{B}$ & $\mathrm{Bi}$ \\
\hline Weigth\% & $90.66 \pm 0.09$ & $6.37 \pm 0.18$ & $2.97 \pm 0.14$ \\
\hline
\end{tabular}

concentration of sodium hydroxide presents some particles inclusions and a rough surface, suggesting a destabilization due to the formation of hydroxides. The samples with 58.5 and $78 \mathrm{~g} / \mathrm{L}$ present the most uniform surfaces. None of these coatings present the cauliflower-like morphology typical for electroless nickel-boron stabilized by lead.

Analyzing the results obtained for coating thickness and surface morphology, the bath with $78 \mathrm{~g} / \mathrm{L}$ of sodium hydroxide stood out as the best candidate. This concentration will be kept in the next section.

\subsection{Coatings characterization}

Cross-section observations by SEM are presented in Fig. 6b. Morphological variations are clearly observable between the outer and the inner part of the film. The thickness of the coating is about $15 \mu \mathrm{m}$ (for $1 \mathrm{~h}$ of plating). The inner part, closer to the substrate presents a columnar morphology on approximately $4 \mu \mathrm{m}$, as is typically observed for electroless NiB coatings. However, the outer part shows a featureless morphology. The morphological variations can be explained by changes of growth mode during the plating process, linked to the action of the stabilizer. Heavy metal ions such as $\mathrm{Pb}^{2+}, \mathrm{Cd}^{2+}, \mathrm{Hg}^{2+}, \mathrm{Bi}^{3+}, \mathrm{Cu}^{2+}$ stabilize the plating bath by depositing on the active metal surface through displacement reaction and thus inhibiting the occurrence of the random reduction of nickel. Baskaran et al. [19] observed that some stabilizers adsorbed on the substrate can limit the lateral growth of electroless $\mathrm{Ni}$, resulting in a columnar deposit. When compared with $\mathrm{Pb}^{2+}$ and $\mathrm{Tl}^{3+}, \mathrm{Bi}^{3+}$ has a much higher reduction potential $(-0.126,-0.336$ and $0.293 \mathrm{~V}$ respectively). The high redox potential of $\mathrm{Bi}^{+3}$ will generate an intense displacement reaction between $\mathrm{Bi}$ and iron at the initiation stage. The Bi atoms adsorbed on the surface then will severely limit the lateral growth of $\mathrm{Ni}$, leading to columnar growth. However, Bi deposition drops later in the plating process, thus allowing lateral growth of $\mathrm{Ni}$. Those results are in concordance with similar results obtained by Chen et al. [20] when studying the role of $\mathrm{Cu}^{2+}$ as a stabilizer for electroless NiP. Cupric ions have a really high redox potential $(0.337 \mathrm{~V})$. In their study $\mathrm{Cu}$ is also preferably deposited in the initial stage: after 2 min of plating, the $\mathrm{Cu}$ content of the coating was 96 wt\% and after 10 minutes Cu represented only $4.5 \mathrm{wt} \%$.

The surface morphology of the coated systems is presented on Fig. 6a. Due to the absence of columnar structure in the outer part of the coating, the electroless nickel-boron coatings stabilized by bismuth

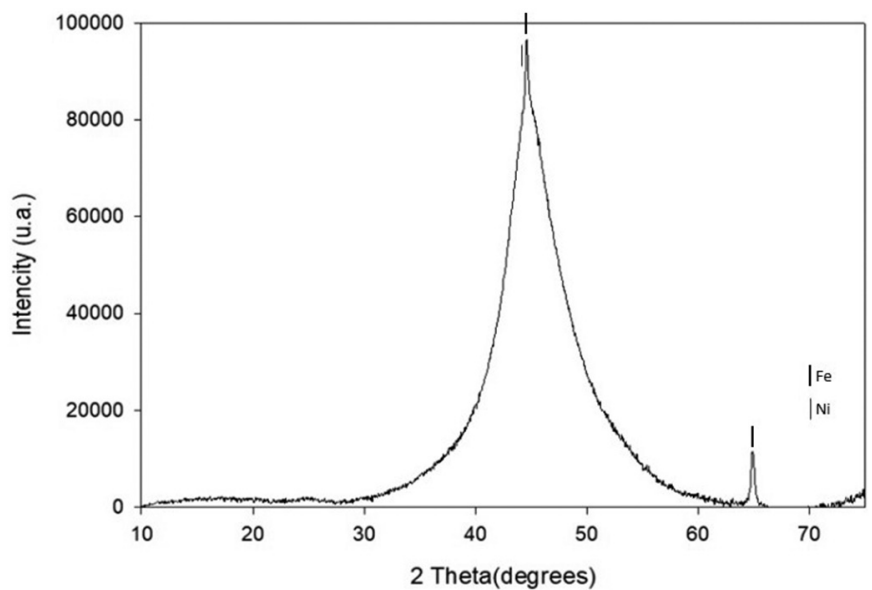

Fig. 7. XRD pattern of electroless nickel-boron stabilized by bismuth.
Table 3

Mechanical properties for electroless nickel boron stabilized by bismuth coatings.

\begin{tabular}{ll} 
Vickers hardness hv(50) & $830 \pm 15$ \\
Knoop hardness hk $(50)$ & $839 \pm 25$ \\
Roughness $-\mathrm{R}_{\mathrm{a}}(\mu \mathrm{m})$ & $0.26 \pm 0.05$ \\
Roughness $-\mathrm{R}_{\mathrm{p}}(\mu \mathrm{m})$ & $0.60 \pm 0.1$ \\
Roughness $-\mathrm{R}_{\mathrm{v}}(\mu \mathrm{m})$ & $0.56 \pm 0.15$ \\
Specific wear rate Ws $\left(\mu \mathrm{m}^{2} / \mathrm{N}\right)$ & 0.67 \\
Friction coefficient $\mu$ & 0.45 \\
First damage $(\mathrm{Lc})(\mathrm{N})$ & 16 \\
Angular cracks $(\mathrm{N})$ & 32 \\
Coating chipping $(\mathrm{N})$ & 75 \\
\hline
\end{tabular}

(NiB-Bi) look more homogeneous and smooth than the typical nickel-boron coatings (NiB-Pb).

The Composition of the coating was determined by ICP-AES after dissolution in aqua regia and is shown in Table 2. On average, the composition is approximately $6.4 \mathrm{wt} \%$ boron and $3 \mathrm{wt} \%$ bismuth, the balance being nickel ( $90.6 \mathrm{wt} \%)$.

EDX cross-section analyses were realized to prove that Bi concentrations are larger in the inner part of the coating (deposited first), due to the intense displacement reaction, and drops with the deposition time. Quantitative data was not obtained due to the low weight of boron atoms, however it was possible to observe that bismuth was present in the first $4 \mu \mathrm{m}$ and it was not detected after that. These results show that bismuth concentration after $4 \mu \mathrm{m}$ of deposition should be smaller than the EDX detection for bismuth ( 1 wt.\%).

Fig. 7 presents X-ray diffraction data for the NiB-Bi coating. The shows only two sharp peaks, at $44.9^{\circ}$ and $64.22^{\circ}$. These peaks represent bcc (body-centered cubic crystal) Fe lattice planes (110) and (200). These peaks are due to the substrate (the penetration depth of $\mathrm{Cu} \mathrm{K \alpha}$

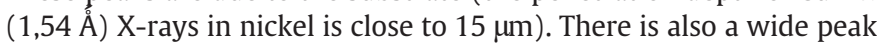
centered on $44^{\circ}$, which corresponds to either nanocrystalline or amorphous nickel and is linked with a supersaturated solution of boron in nickel. The structural state of $\mathrm{NiB}$ is mainly determined by the boron content that varies with the bath composition, bath temperature and principally with the type of reductant adopted in the process. Coatings reduced by borohydride [12] are usually amorphous due to their high boron content. The nickel-boron phase diagram predicts the coexistence of $\mathrm{Ni}_{3} \mathrm{~B}$ and $\mathrm{Ni}_{2} \mathrm{~B}$ between 5.8 and $8.5 \mathrm{wt} \% \mathrm{~B}$. However, electroless plating does not bring enough energy to the system to allow crystallization of the equilibrium phases because the diffusion of boron in nickel is very limited [21]. The boron content in the NiB-Bi coatings is higher than $6 \mathrm{wt} \%$, so the X-ray amorphous structure was expected from

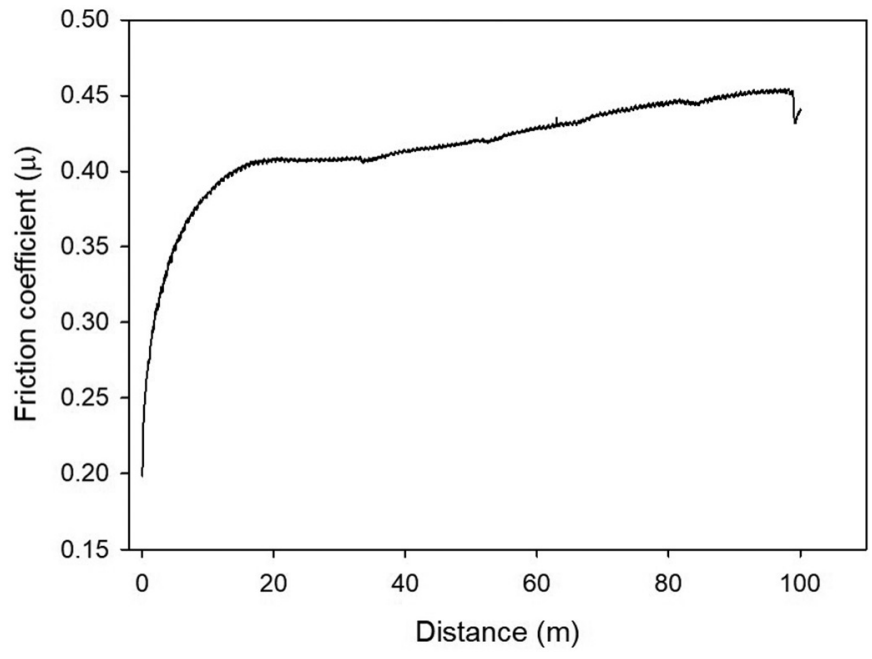

Fig. 8. Friction coefficient evolution of NiB-Bi samples during the ball-on-disc test in nonlubricated conditions. 

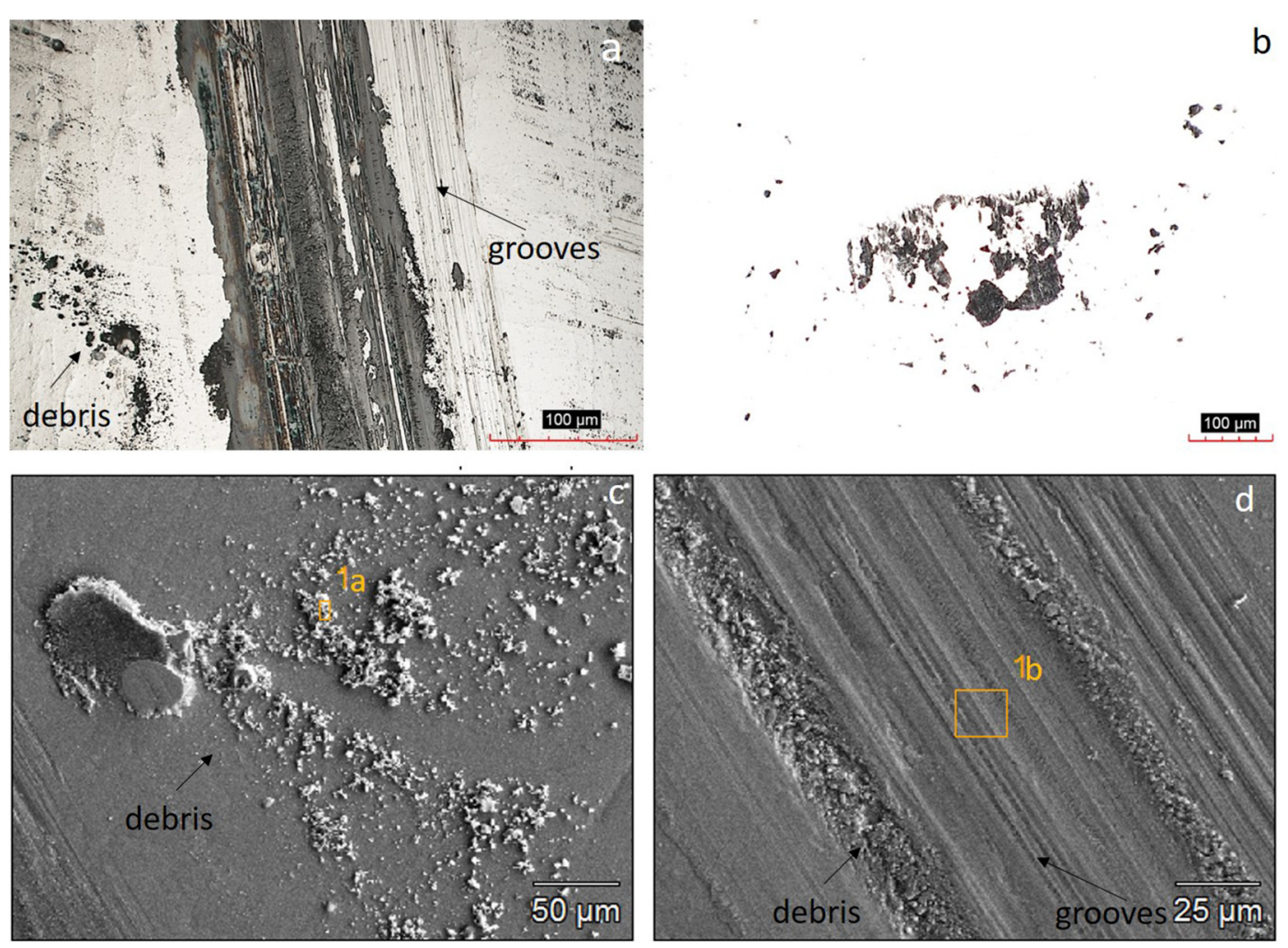

Fig. 9. (a) sliding wear tracks on electroless NiB-Bi, (b) alumina ball surface after test, (c) debris particles and (d) wear tracks grooves.

previous results obtained for coatings stabilized by lead [22]. This shows that the co-deposition of bismuth did not interfere in the coating structure.

Surface roughness has a considerable impact on coatings properties, such as fatigue behavior, corrosion resistance, wear behavior, light reflection, heat transmission, electrical conductivity, etc. [23]. Roughness values are shown in Table 3. The parameters chosen to represent the roughness in this study are $R_{a}$ (arithmetic average of the height of every point of the surface), $R_{p}$ (maximum peak height) and $R_{v}$ (maximum valley depth). Ra is the most used roughness parameter, which facilitates comparisons with other works. Rp represents the height of the highest peak from the mean line and Rv represents the deepest valleys. High values of Rp and Rv can signify deposition defects. As expected from surface morphology observation, roughness values are on average very low and do not present important standard deviations.

These results show once more the good stability of this lead-free bath. A low value of surface roughness indicates a stable bath because an electroless nickel plating bath without a proper stabilization system will produce a lot of fine nickel flakes shortly after the plating is initiated [24], some of these particles can then be trapped in the coating during its growth consequently increasing the surface roughness.

Standard Vickers and Knoop hardness tests were conducted on the cross-section of the sample with a load of $50 \mathrm{gf}$. The average hardness of 10 measures is shown in Table 3. The hardness of electroless nickel-boron coatings is usually much higher than that of nickelphosphorous, in the as-plated state [25]. The hardness presented for this new coating composition is impressive $830 \mathrm{hv}_{50}$. In addition, the

Table 4

Worn surface and debris chemical composition.

\begin{tabular}{llllll}
\hline wt. & $\mathrm{C}$ & $\mathrm{O}$ & $\mathrm{Al}$ & $\mathrm{Fe}$ & $\mathrm{Ni}$ \\
\hline 1a & $1.2 \pm 0.3$ & $13.6 \pm 0.6$ & $0.5 \pm 0.1$ & $0.8 \pm 0.2$ & $83.9 \pm 1.8$ \\
1b & $0.6 \pm 0.2$ & $7.8 \pm 0.3$ & $0.7 \pm 0.1$ & $1.0 \pm 0.2$ & $89.9 \pm 0.9$ \\
\hline
\end{tabular}

hardness values, that are already impressive, could be increased with adequate heat treatment [22].

The wear data obtained for electroless NiB-Bi deposits, using ballon-disc apparatus in non-lubricated conditions, are given in Table 3. The friction coefficient value (0.45) presented in Table 3 is obtained after $100 \mathrm{~m}$ of test. Friction coefficient evolution with test distance can be seen in Fig. 8. Due the really smooth surface (absence of columnar surface), the contact surface does not change with time and the friction coefficient varies by only $12 \%$ between 20 and $100 \mathrm{~m}$. Comparing with other nickel alloys and coatings [26-28] measured in the same conditions, NiB-Bi has an impressively low friction coefficient. These properties are possible due to the presence of boron, as boron atoms can, at the same time, increase hardness and lubricity.

The specific wear rate $\left(0.67 \mu \mathrm{m}^{2} / \mathrm{N}\right)$ of these coatings is directly related to hardness and is remarkably low. The wear mechanisms can be determined from observation of the worn surfaces after the ball-ondisc test. Fig. 9a presents the worn surface of the coating. From it, it can be seen that, after wear, the samples exhibit an almost bright and smooth finish with fine abrasion grooves along the sliding direction and a region characterized by the presence of added debris. In addition, due to the low roughness of this coating debris particle can be found on the adjacent regions while, in the case of traditional $\mathrm{NiB}-\mathrm{Pb}$, debris stay retained in the cauliflower surface. Fig. 9c shows the debris particles in neighboring regions; the chemical composition of these particles was

Table 5

Comparative for electroless nickel boron stabilized by lead and bismuth coatings.

\begin{tabular}{lll}
\hline & NiB-Pb & NiB-Bi \\
\hline Thickness $(\mu \mathrm{m})$ & $16.02[39]$ & 15,0 \\
Ra $(\mu \mathrm{m})$ & $0.71[39]$ & 0.26 \\
Hardness hv s0 $_{50}$ & $833[44]$ & 830 \\
Lc $(\mathrm{N})$ & 25 & 16 \\
Friction coefficient & 0.45 & 0.45 \\
Specific wear rate Ws $\left(\mu \mathrm{m}^{2} / \mathrm{N}\right)$ & 0.63 & 0.67 \\
Corroded surface $(\%)$ & 21.1 & 32.6 \\
\hline
\end{tabular}



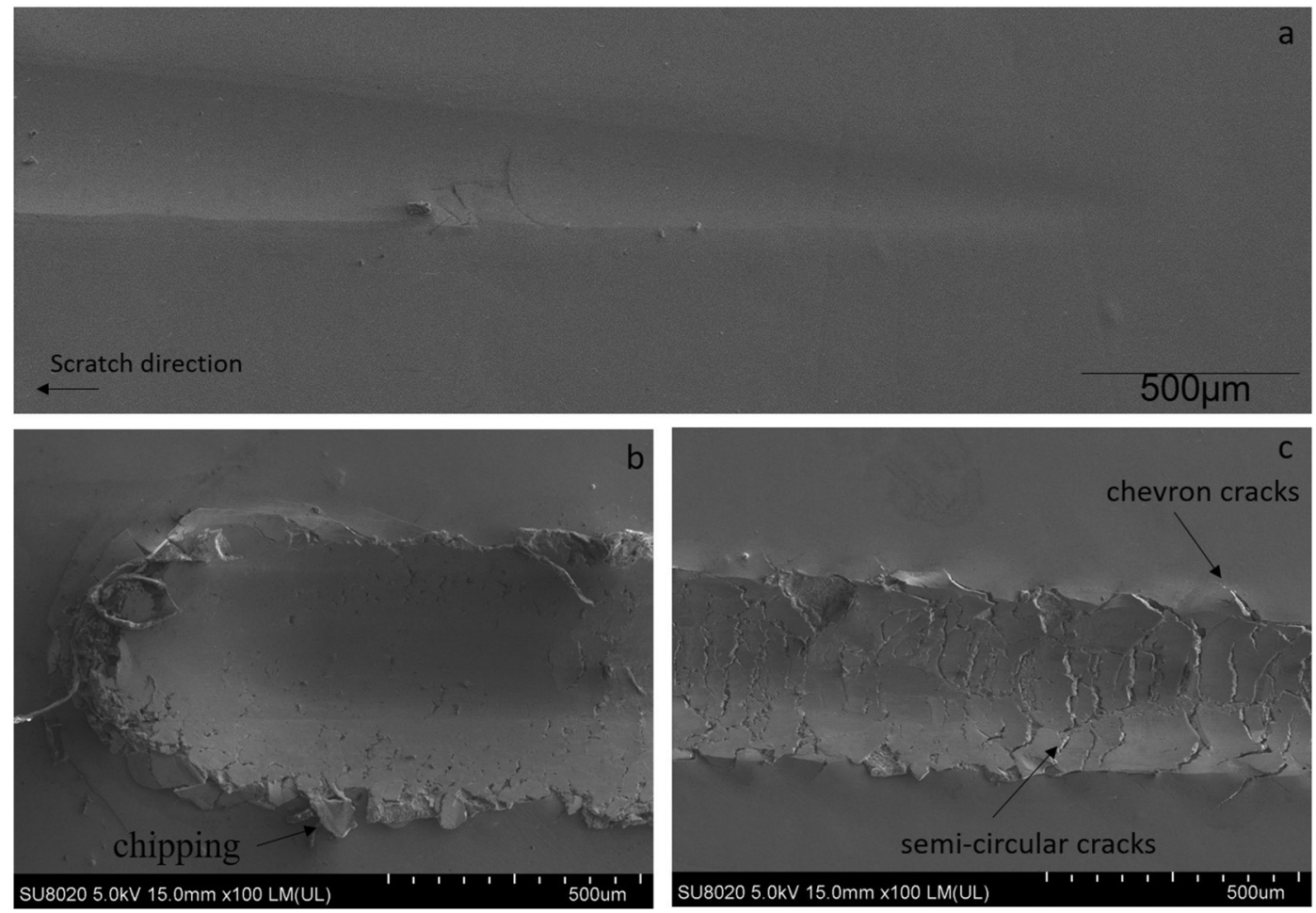

Fig. 10. Electroless NiB-Bi scratched coating surface; (a) scratch beginning; (b) detail showing coating chipping; (c) detail showing coating chevron cracks and semi-circular cracks.

analyzed (Table 4 zone 1a) and showed the oxidation of nickel caused by the heating during the test. Adhesion between alumina balls and $\mathrm{Ni}$ coatings should not be expected due the chemical differences of these two materials. However, the presence of a layer of coating on the alumina ball can be observed in the Fig. 9b, the explanation for this is the oxidation of coating debris: once $\mathrm{Ni}$ is oxidized, the adhesion between Ni oxide and Al oxide may occur. It's important to observe that adhesion takes place also in lateral regions, as well as the debris presence. Fig. 9d shows a detailed image of the worn surface and delamination and cracking are not observed at all. Table 4 shows proves the oxide presence in the debris and also in the worn surface. In conclusion, abrasive wear can be identified as the predominant wear phenomenon, with adhesive wear arising after debris oxidation. Similar wear mechanisms

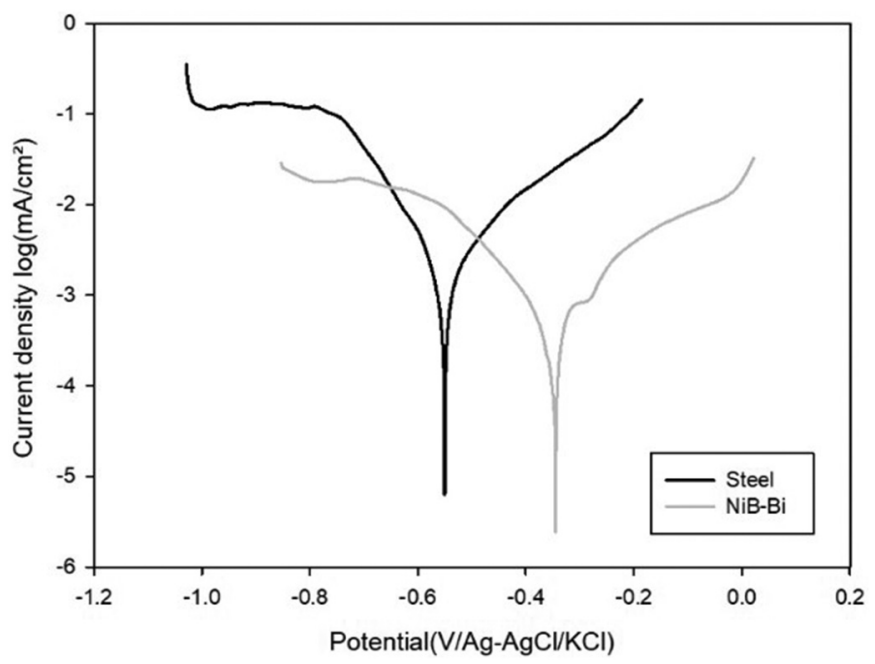

Fig. 11. Potentiodynamic polarization curves, $0.1 \mathrm{M} \mathrm{NaCl}$, of electroless NiB-Bi and mild steel. have been reported for other electroless nickel coatings in the literature [29,30]. (See Table 5.)

Scratch tests were used in order to estimate the adhesion of the deposits under external solicitations. The damage features were determined by observation of the residual scratches, as shown in Fig. 10.

Table 3 presents the critical load for each type of intolerable damage, obtained by a combination of acoustic emission and microscope observation. The first damage was transverse semi-circular cracks that appear at $16 \mathrm{~N}$ (before this damage just plastic deformation can be observed (Fig. 10a), while chevron cracks appear at $32 \mathrm{~N}$ (Fig. 10c) and chipping is present for loads superior to $75 \mathrm{~N}$ (Fig. 10b). Semi-circular and chevron cracks are a cohesive failure that occurs by tensile stress behind the stylus. Chipping corresponds to the adhesive failure of the coatings caused by the high substrate deformation happening without a coating deformation in the case of high load. The results indicate a good adhesion and scratch resistance and none of the coatings tested presented complete failure or scaling.

The electrochemical characteristics of the NiB-Bi coatings and mild steel were investigated by potentiodynamic polarization technique. Results are shown in Fig. 11.

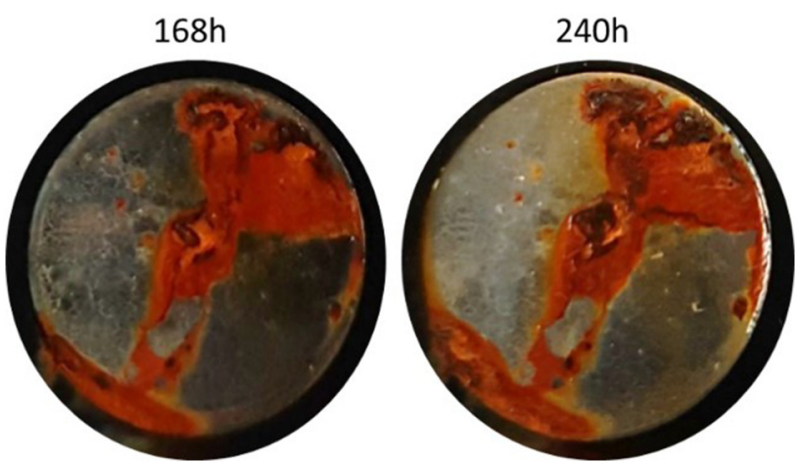

Fig. 12. Surface aspect of electroless NiB-Bi $15 \mu \mathrm{m}$ coatings after $168 \mathrm{~h}$ and $240 \mathrm{~h}$ of salts spray test. 
Potentiodynamic polarization was performed in $0.1 \mathrm{M} \mathrm{NaCl}$ solution for coatings with $15 \mu \mathrm{m}$ thickness on a mild steel substrate. When compared to the bare steel, coated samples present a better behavior: a positive shift in the corrosion potentials ( $\mathrm{E}_{\text {corr }}$ ), from $0.55 \mathrm{~V} \mathrm{Vs} \mathrm{Ag/AgCl} \mathrm{(KCl}$ saturated) in the case of bare steel to $0.34 \mathrm{~V} \mathrm{Vs} \mathrm{Ag} / \mathrm{AgCl}$ ( $\mathrm{KCl}$ saturated) for coated samples, and a decrease in the corrosion current densities ( $i_{\text {corr }}$ ) close to 1 order of magnitude lower than the bare steel. Once more, the results suggest that the deposited layers completely cover the substrate [31]. The increase of the $\mathrm{E}_{\text {corr }}$ in the presence of coatings can then be attributed to presence of the coating on the steel surface (Ni is nobler than Fe).

Comparing the anodic polarization curves the coated systems present a tendency to passivation up to $-0.28 \mathrm{~V} \mathrm{Vs} \mathrm{Ag} / \mathrm{AgCl}$ ( $\mathrm{KCl}$ saturated); after that point, the shape for the bare steel is similar to the shape for coated sample. This plateau might indicate that a passive state is temporarily reached for those systems. This kind of passive-transpassive behavior is often observed for NiP coatings [25,26,32].

Neutral salt spray test was carried out according to ASTM B117-07. The tests were conducted for a variety of time periods ranging from $0.5 \mathrm{~h}$ to $336 \mathrm{~h}$ (14 days) with intermediate periods. There were no noticeable corrosion pits on the surface of the mild steel-coated samples until $48 \mathrm{~h}$, after which the NiB-Bi samples started to corrode. For the bare mild steel, corrosion started after $1 \mathrm{~h}$ and the surface was completely corroded after $8 \mathrm{~h}$ [35]. The aspect of coated samples after 168 and 240 h of salt spray exposure is shown in Fig. 12. After 7 days in neutral salt spray, the NiB-Bi samples presented $29.5 \%$ of corroded surface and after 3 more days the corroded surface increases to $32.6 \%$. The salts spray results confirm the outcomes obtained by the polarization tests. NiB-Bi samples increase the corrosion resistance of mild steel samples. However, a better behavior was expected after the morphological analysis: NiB-Bi does not present the typical columnar structure that is frequently described as a preferential way for substrate corrosion.

\section{Comparison of electroless NiB-Bi and NiB-Pb}

Among electroless coatings, $\mathrm{NiB}$ is known as the best candidate for mechanical and tribological properties when compared to other types of electroless coatings, such as NiP. In this section the properties of the new $\mathrm{NiB}$ with bismuth stabilizer, are compared with those of $\mathrm{NiB}$ coatings stabilized by toxic metals, from the literature.

From a morphological point of view, NiB-Bi coatings present morphologic variations in the film between the outer part and the inner part. NiB-Pb presents a completely columnar structure [22,36,37]. As explained before, this difference is caused by the high redox potential of $\mathrm{Bi}^{+3}$ compared with $\mathrm{Pb}^{2+}$. The thickness of NiB-Bi coating is about 15 $\mu \mathrm{m}$ for $1 \mathrm{~h}$ of deposition while the previous NiB-Pb coatings present a slightly higher plating rate,(between $15 \mu \mathrm{m}$ and $18 \mu \mathrm{m}$ per hour) [38-40].The typical cauliflower-like structure from $\mathrm{NiB}-\mathrm{Pb}$ is not really apparent in the case of NiB-Bi surface morphology. These morphological changes will also affect the applications of the new coatings. In one side, due to the smooth surface, these coatings have a better aspect and a bright surface, this opens a new market where appearance is important. In addition, this less rough surface can be more precise in dimension and ideal for applications where dimensional tolerances are really strict. On the other side, the decrease of roughness will most probably lead to an increase in wear due to higher adhesion, and increased friction, as well as to the loss of the lubricant retaining properties of the cauliflower-like texture.

Coatings reduced by borohydride [8] are usually amorphous, in as plated state, due to the high boron content. Both, NiB-Pb $[4,41,42]$ and $\mathrm{NiB}-\mathrm{Bi}$ present a wide peak centered on $44^{\circ}$ which corresponds to either nanocrystalline or amorphous supersaturated nickel. The coating obtained from a bath stabilized with bismuth presents a higher concentration of $\mathrm{Bi}$ when compared with the lead concentration in the $\mathrm{NiB}-\mathrm{Pb}$ samples, on average, the NiB-Pb composition is approximately $6 \mathrm{wt} \%$ boron, 1 wt\% lead, and 93 wt\% nickel [38]. However, when compared with coatings that contain thallium, the concentration of bismuth is comparable [14,25].

Table 4 summarizes the properties of electroless coatings stabilized by bismuth and lead. All the references used to create Table 4 are from the same group and all the characterizations were realized in the same conditions with the same equipment that was presented in the materials and methods section. As expected, based on the surface morphology, the new coatings are smoother than coatings stabilized by lead ( Ra $0.71 \mu \mathrm{m}$ ) [38]. The microhardness of electroless NiB-Pb coating is of the order of 833(hv50) [43], so, both coatings have the same hardness. Tribological properties like Ws are really close in the case of both stabilizers. The friction coefficient of the $\mathrm{NiB}-\mathrm{Pb}[10,41]$ and $\mathrm{NiB}-\mathrm{Bi}$ coatings are the same. The larger difference in terms of properties is observed for the adhesion: NiB-Bi coatings submitted to scratch test present first damage after $16 \mathrm{~N}$ while $\mathrm{NiB}-\mathrm{Pb}$ coatings present the first damage close to $25 \mathrm{~N}$ or higher [10,42]. However, this should not be a problem for future applications of these coating as NiP coatings, that are largely used in the industry, present first damage close to $15 \mathrm{~N}$ when submitted to scratch test [42]. Corrosion behavior of the new coatings is slightly inferior when compared with the traditional $\mathrm{NiB}-\mathrm{Pb}$, as presented in Table 4: when exposed to salt spray test the new coatings presented a larger corroded surface.

\section{Conclusion}

Electroless Nickel-Boron coatings were prepared using a new environmentally-friendly bath stabilized by bismuth. These systems do not use either lead or thallium and can successfully replace traditional lead-containing chemistry for different applications. These new coatings, when compared with the classical bath (NiB-Pb), present modified chemical composition, growth mode, morphology, and mechanical properties.

The morphology of the new coatings does not present the cauliflower-like surface texture typical for electroless nickel boron coating. A change in the cross-section morphology was also observed. The new coatings present a cross-section with two dissimilar regions: one has a columnar structure, while the second one is featureless. Regarding the mechanical properties, the new coatings have interesting values of roughness, hardness and wear rate. The adhesion behavior obtained by scratch test is inferior when compared with the classical coating. Corrosion results are not as good as expected after morphological analysis, however coatings can be used to protect mild steel.

The thallium-and lead-free chemistry meets ELV 2000/53/EC and RoHS 2002/95/EC compliance. In addition, this new system operates in the same way as conventional electroless nickel-boron plating, which facilitates the use of this new method in the industry.

\section{References}

[1] K.I. Popov, S. Djokic, B. Grgur, Metal deposition without an external current, Fundam. Asp. Electrometall, Kluwer Academic Publishers, New York 2002, pp. 249-270.

[2] K. Krishnan, S. John, K. Srinivasan, J. Praveen, M. Ganesan, P. Kavimani, An overall aspect of electroless Ni-P depositions-a review article, Metall. Mater. Trans. A. 37 (2006) 1917-1926, https://doi.org/10.1007/s11661-006-0134-7.

[3] J.C. Warf, K.H. Schaltegger, Method of coating steel with nickel-boron, US Patent 2 (726) (1955) 170.

[4] Y.N. Bekish, S.K. Poznyak, L.S. Tsybulskaya, T.V. Gaevskaya, Electrodeposited Ni-B alloy coatings: structure, corrosion resistance and mechanical properties, Electrochim. Acta 55 (2010) 2223-2231, https://doi.org/10.1016/j.electacta.2009. 11.069.

[5] E. Correa, A.A. Zuleta, L. Guerra, M.A. Gómez, J.G. Castaño, F. Echeverría, H. Liu, A Baron-Wiecheć, T. Hashimoto, P. Skeldon, G.E. Thompson, Coating development during electroless Ni-B plating on magnesium and AZ91D alloy, Surf. Coat. Technol. 232 (2013) 784-794, https://doi.org/10.1016/j.surfcoat.2013.06.100.

[6] K.H. Lee, D. Chang, S.C. Kwon, Properties of electrodeposited nanocrystalline Ni-B alloy films, Electrochim. Acta 50 (2005) 4538-4543, https://doi.org/10.1016/j. electacta.2004.03.067. 
[7] O.R. Monteiro, S. Murugesan, V. Khabashesku, Electroplated Ni-B films and Ni-B metal matrix diamond nanocomposite coatings, Surf. Coat. Technol. 272 (2015) 291-297, https://doi.org/10.1016/j.surfcoat.2015.03.049.

[8] T.S.N. Sankara Narayanan, S.K. Seshadri, Formation and characterization of borohydride reduced electroless nickel deposits, J. Alloys Compd. 365 (2004) 197-205, https://doi.org/10.1016/S0925-8388(03)00680-7.

[9] A.A.B.J. Bielinski, J. Krol, Inorganic additives in the solution for electroless nicke-boron alloy deposition, Bull. Electrochem. 6 (1990) 828-831(doi: 0256-1654/90/3-50).

[10] K.M. Gorbunova, M.V. Ivanov, V.P. Moiseev, Electroless deposition of nickel-boron alloys: mechanism of process, structure, and some properties of deposits, J. Electrochem. Soc. 120 (1973) 613-618, https://doi.org/10.1149/1.2403514.

[11] B. Hu, R. Sun, G. Yu, L. Liu, Z. Xie, X. He, X. Zhang, Effect of bath pH and stabilizer on electroless nickel plating of magnesium alloys, Surf. Coat. Technol. 228 (2013) 84-91, https://doi.org/10.1016/j.surfcoat.2013.04.011.

[12] H. Li, H. Li, W. Dai, M. Qiao, Preparation of the Ni-B amorphous alloys with variable boron content and its correlation to the hydrogenation activity, Appl. Catal. A Gen. 238 (2002) 119-130, https://doi.org/10.1016/S0926-860X(02)00342-3.

13] K. Krishnaveni, T.S.N. Sankara Narayanan, S.K. Seshadri, Electrodeposited Ni-B coatings: formation and evaluation of hardness and wear resistance, Mater. Chem. Phys. 99 (2006) 300-308, https://doi.org/10.1016/j.matchemphys.2005.10.028.

[14] F. Delaunois, J.P. Petitjean, M. Jacob-Dulière, P. Lienard, M. Jacob-Duliere, Autocatalytic electroless nickel-boron plating on light alloys, Surf. Coat. Technol. 124 (2000) 201-209, https://doi.org/10.1016/S0257-8972(99)00621-0.

[15] L. Bonin, V.Vitry, F. Delaunois, The tin stabilization effect on the microstructure, corrosion and wear resistance of electroless NiB coatings, Surf. Coat. Technol. 357 (2019) 353-363, https://doi.org/10.1016/j.surfcoat.2018.10.011.

[16] W.J. Cheong, B.L. Luan, D.W. Shoesmith, The effects of stabilizers on the bath stability of electroless Ni deposition and the deposit, Appl. Surf. Sci. 229 (2004) 282-300 https://doi.org/10.1016/j.apsusc.2004.02.003.

[17] B. Zhang, Green electroless plating, Amorph. Nano Alloy. Electroless Depos. 1st editElsevier Ltd, 2016 https://doi.org/10.1016/B978-0-12-802685-4/00007-8.

[18] K.L. Lin, J.W. Hwang, Effect of thiourea and lead acetate on the deposition of electroless nickel, Mater. Chem. Phys. 76 (2002) 204-211, https://doi.org/10.1016/S02540584(01)00516-8.

[19] I. Baskaran, T.S.N.S. Narayanan, A. Stephen, Effect of accelerators and stabilizers on the formation and characteristics of electroless Ni-P deposits, Mater. Chem. Phys. 99 (2006) 117-126, https://doi.org/10.1016/j.matchemphys.2005.10.001.

[20] C. Chen, B. Chen, L. Hong, Role of $\mathrm{Cu} 2+$ as an additive in an Electroless nickel phosphorus plating system : a stabilizer or a Codeposit ? Chem. Mater. 18 (2006) 2959-2968, https://doi.org/10.1021/cm0527571.

[21] V. Vitry, A.F. Kanta, J. Dille, F. Delaunois, Structural state of electroless nickel-boron deposits (5wt.\% B): characterization by XRD and TEM, Surf. Coat. Technol. 206 (2012) 3444-3449, https://doi.org/10.1016/j.surfcoat.2012.02.003.

[22] V. Vitry, F. Delaunois, C. Dumortier, Mechanical properties and scratch test resistance of nickel-boron coated aluminium alloy after heat treatments, Surf. Coat Technol. 202 (2008) 3316-3324, https://doi.org/10.1016/j.surfcoat.2007.12.001.

[23] P. Sahoo, Optimization of Electroless Ni-P coatings based on surface roughness, Tribol. Online. 3 (2008) 6-11, https://doi.org/10.2474/trol3.1.

[24] X. Yin, L. Hong, B.H. Chen, T.M. Ko, Modeling the stability of electroless plating bath diffusion of nickel colloidal particles from the plating frontier, J. Colloid Interface Sci. 262 (2003) 89-96, https://doi.org/10.1016/S0021-9797(03)00191-7.

[25] V. Vitry, A. Sens, F. Delaunois, Comparison of various Electroless nickel coatings on steel: structure, hardness and abrasion resistance, Mater. Sci. Forum 783-786 (2014) 1405-1413, https://doi.org/10.4028/www.scientific.net/MSF.783-786.1405.

[26] J.D. Li, X. Ã, J. Dai, Z. Huang, R. Tyagi, Tribology international effect of surface laser texture on friction properties of nickel-based composite, Tribol. Int. 43 (2010) 1193-1199, https://doi.org/10.1016/j.triboint.2009.12.044.
[27] A.S.M.A. Haseeb, U. Albers, K. Bade, Friction and wear characteristics of electrodeposited nanocrystalline nickel - tungsten alloy films, Wear 264 (2008) 106-112, https://doi.org/10.1016/j.wear.2007.02.004.

[28] J.L. Li, D.S. Xiong, Tribological properties of nickel-based self-lubricating composite at elevated temperature and counterface material selection, Wear 265 (2008) 533-539, https://doi.org/10.1016/j.wear.2007.09.005.

[29] E. Correa, A.A. Zuleta, L. Guerra, M.A. Gómez, J.G. Castaño, F. Echeverría, H. Liu, P. Skeldon, G.E. Thompson, Tribological behavior of electroless Ni-B coatings on magnesium and AZ91D alloy, Wear 305 (2013) 115-123, https://doi.org/10.1016/j. wear.2013.06.004.

[30] J.M. Fildes, S.J. Meyers, C.P. Mulligan, R. Kilaparti, Evaluation of the wear and abrasion resistance of hard coatings by ball-on-three-disk test methods-a case study, Wear 302 (2013) 1040-1049, https://doi.org/10.1016/j.wear.2012.11.018.

[31] Z.-C. Wang, L. Yu, Z.-B. Qi, G.-L. Song, Electroless nickel-boron plating to improve the corrosion resistance of magnesium (Mg) alloys, Corros. Prev. Magnes. Alloy. (2013) 370-392, https://doi.org/10.1533/9780857098962.3.370.

[32] M. Sribalaji, P. Arunkumar, K.S. Babu, A.K. Keshri, Crystallization mechanism and corrosion property of electroless nickel phosphorus coating during intermediate temperature oxidation, Appl. Surf. Sci. 355 (2015) 112-120, https://doi.org/10. 1016/j.apsusc.2015.07.061.

[35] L. Bonin, V. Vitry, F. Delaunois, Corrosion behaviour of electroless high boron-mid phosphorous nickel duplex coatings in the as-plated and heat-treated states in $\mathrm{NaCl}, \mathrm{H} 2 \mathrm{SO} 4, \mathrm{NaOH}$ and Na2SO4 media, Mater. Chem. Phys. 208 (2018) 77-84, https://doi.org/10.1016/j.matchemphys.2017.12.030.

[36] V. Vitry, L. Bonin, Increase of boron content in electroless nickel-boron coating by modification of plating conditions, Surf. Coat. Technol. 311 (2017) 164-171, https://doi.org/10.1016/j.surfcoat.2017.01.009.

[37] V. Vitry, E. Francq, L. Bonin, V. Vitry, Mechanical properties of heat-treated duplex electroless nickel coatings mechanical properties of heat-treated duplex electroless nickel coatings, Surf. Eng. 0 (2018) 1-9, https://doi.org/10.1080/02670844.2018. 1463679 .

[38] L. Bonin, N. Bains, V. Vitry, A.J. Cobley, Electroless Deposition of Nickel-Boron Coatings Using Low Frequency Ultrasonic Agitation : Effect of Ultrasonic Frequency on the Coatings, vol. 77, 2017 61-68, https://doi.org/10.1016/j.ultras. 2017.01.021.

[39] L. Bonin, V. Vitry, Mechanical and wear characterization of electroless nickel mono and bilayers and high boron-mid phosphorus electroless nickel duplex coatings, Surf. Coat. Technol. 307 (2016) 957-962, https://doi.org/10.1016/j.surfcoat.2016. 10.021.

[40] V.V. Vitry, A. Sens, A.F. Kanta, F. Delaunois, Experimental study on the formation and growth of electroless nickel- boron coatings from borohydride-reduced bath on mild steel, Appl. Surf. Sci. 263 (2012) 1-21, https://doi.org/10.1016/j.apsusc.2012. 09.126 .

[41] H. Li, H. Li, W.L. Dai, W. Wang, Z. Fang, J.F. Deng, XPS studies on surface electronic characteristics of Ni-B and Ni-P amorphous alloy and its correlation to their catalytic properties, Appl. Surf. Sci. 152 (1999) 25-34, https://doi.org/10.1016/S0169-4332 (99)00294-9.

[42] J. Guo, Y. Hou, C. Yang, Y. Wang, L. Wang, Effects of nickel ethylenediamine complex on the preparation of Ni-B amorphous alloy catalyst with ultrasonic assistance, Mater. Lett. 67 (2012) 151-153, https://doi.org/10.1016/j.matlet.2011.09. 059.

[43] V. Vitry, L. Bonin, Effect of temperature on ultrasound-assisted electroless nickelboron plating, Ultrason. Sonochem. (2019) https://doi.org/10.1016/j.ultsonch. 2019.04.027.

[44] L. Bonin, V. Vitry, Formation and characterization of multilayers borohydride and hipophosphite reduced electroless nickel deposits, Electrochim. Acta 243 (2017) 7-17, https://doi.org/10.1016/S0925-8388(03)00680-7. 